\title{
HAZARD PISIKOSOSIAL DAN UPAYA YANG DAPAT DI LAKUKAN UNTUK MENCEGAH HAZARD PISIKOSOSIAL DI LINGKUNGAN KERJA \\ Nabila Rahmadhani \\ @rahmadhaninabila2@gmail.com
}

\begin{abstract}
The work environment is a place where someone does work. One of the hazards that exist in the workplace is psychosocial hazards. Many hazard factors in the work environment can cause health problems and psychosocial factors. Hazards are all sources, situations or activities that have the potential to cause injury (work accidents) or occupational diseases. Psychosocial problems are psychological or psychological problems that arise as a result of social change.

Keywords: psychological, social hazard. Efforts to prevent physical social hazards

\section{Abstrak}

Lingkungan kerja merupakan tempat dimana seseorang melakukan pekerjaan. Salah satu bahaya yang ada ditempat kerja adalah bahaya psikososial Banyak faktor bahaya di lingkungan kerja yang dapat mengakibatkan gangguan kesehatan dan faktor psikososial. Hazard merupakan semua sumber, situasi ataupun aktivitas yang berpotensi menimbulkan cedera (kecelakaan kerja) atau penyakit akibat kerja. Masalah psikososial merupakan masalah psikis atau kejiwaan yang timbul sebagai akibat terjadinya perubahan sosial.
\end{abstract}

Kata kunci: hazard pisikososial. Upaya mencegah hazard pisikososial 


\section{Latar Belakang}

Menurut International Labour Organization (ILO) kesehatan keselamatan kerja atau Occupational Safety and Health adalah meningkatan dan memelihara derajat tertinggi semua pekerja baik secara fisik, mental, dan kesejahteraan sosial di semua jenis pekerjaan, mencegah terjadinya gangguan kesehatan yang diakibatkan oleh pekerjaan, melindungi pekerja pada setiap pekerjaan dari risiko yang timbul dari faktor-faktor yang dapat mengganggu kesehatan, menempatkan dan memelihara pekerja di lingkungan kerja yang sesuai dengan kondisi fisologis dan psikologis pekerja dan untuk menciptakan kesesuaian antara pekerjaan dengan pekerja dan setiap orang dengan tugasnya.

Dari uraian mengenai definisi di atas, K3 dapat dirumuskan tujuan K3. Tujuan utama pelaksanaan K3 ada dua. Pertama, menciptakan lingkungan kerja yang selamat dengan melakukan penilaian secara kualitatif dan kuantitatif. Kedua, menciptakan kondisi yang sehat bagi karyawan, keluarga dan masyarakat sekitarnya melalui upaya promotif, preventif, kuratif dan rehabilitatif

Lingkungan adalah keseluruhan atau aspek dari gejala fisik dan sosial kultural yang mempengaruhi individu. Kerja adalah aktifitas manusia baik fisik maupun mental yang didasarkan pada bawaan dan mempunyai tujuan untuk mendapatkan kepuasan (As'ad, 1998). Lingkungan kerja menurut Sedarmayanti (2011) adalah semua keadaan yang terdapat disekitar tempat keja yang akan memengaruhi pegawai baik secara langsung maupun tidak langsung

Masalah keselamatan dan kesehatan kerja merupakan salah satu masalah dunia. Menurut Joint ILO/ WHO Committee on Ocupational Health (2013). Kesehatan kerja bertujuan untuk promosi dan pemeliharaan tingkat tertinggi kesehatan fisik, mental dan sosial dari pekerjaan dalam berbagai jenis pekerjaan, mencegah penyakit yang diakibatkan dari kondisi pekerjaan mereka ditempat kerja dari risiko yang diakibatkan faktor-faktor yang mengganggu kesehatan; menempatkan dan memelihara lingkungan pekerjaan pekerja baik kemampuan fisiologis maupun psikologis pekerja dan menerapkannya kepada pekerja disetiap pekerjaannnya.

Keselamatan dan Kesehatan Kerja sebagai suatu program didasari pendekatan ilmiah dalam upaya mencegah atau memperkecil terjadinya bahaya (hazard) dan risiko (risk) terjadinya penyakit dan kecelakaan, maupun kerugian-kerugian lainya yang mungkin terjadi. Jadi dapat dikatakan bahwa Keselamatan dan Kesehatan Kerja adalah suatu pendekatan ilmiah dan praktis dalam mengatasi potensi bahaya dan risiko kesehatan dan keselamatan yang mungkin terjadi.( Rijanto, 2010 ). Keselamatan pasien adalah bebas dari cideran fisik dan psikologis yang menjamin keselamatan pasien, melalui penetapan system operasional, meminilisasi terjadinya kesalahan, mengurangi rasa tidak aman pasien dalam sistem perawatan kesehatan dan meningkatkan pelayanan yang optimal (canadian nursing association, 
2004) International council nurse (2002) mengatakan bahwa keselamtan pasien merupakan hal mendasar dalam mutu pelayanan keperawatan.

Salah satu bahaya yang ada ditempat kerja adalah bahaya psikososial. Bahaya psikososial dapat menyebabkan stres pada pekerja, hal ini dapat disebabkan oleh akumulasi stressor pada situasi kerja di tempat kerja. Misalnya, tuntutan pekerjaan dapat memicu timbulnya stres di tempat kerja. Menurut Randall R. Ross (1994), disebutkan bahwa stres kerja terjadi akibat adanya interaksi antara kondisi kerja dengan karakteristik pekerja dimana tuntutan pekerjaan melebihi kemampuan para pekerja. Hasil penelitian yang dilakukan oleh Wayne L. Chappelle (2014) menyebutkan bahwa stres kerja disebabkan karena upah rendah, tugas-tugas tambahan, sistem shift kerja, dan jam kerja yang panjang.

Menurut Myers, 2012 mengatakan bahwa penerapan patient safety sangat tergantung dari pengetahuan petugas kesehatan. Apabila petugas menerapkan patient safety didasari oleh pengetahuan yang memadai, maka penerapan patient safety oleh petugas tersebut akan bersif langgeng (long lasting).

\section{Metode}

Metode yang di gunakan pengkaji dalam melakukan penulisan kajian ini adalah dengan melakukukan pengkajian menggunakan metode literature review. Denga metode literature review penulis mengumpulkan sumber berdasarkan dari berbagai sumber bacaan yang ada berupa, buku bacaan, jurnal, tesis maupun ebook yang berhubunga dengan hazard pisikososial dan upaya yang dapat dilakukan untuk mencegah terjadinya hazard pisikososial agar kasus terjadinya hazard pisikososial di indonesia dapat di tanggulangi dengan baik dan menjadikan kasus hazard pisikososial sebagai kasus yang sangat jarang terjadi di lingkungan kerja terutama di rumah sakit.

Kajian ini juga merupakan kajian bebas dimana adalah kajian ini bersifat bebas di mana kajian ini melakukan pengkajian dengan melakukan perbandingan anatar artikel-artikel yang telah di dapat kan yang berhubungan dengan hazard pisikososial dan setelah melakukan perbandingan hasil dari perbandingan tersebut lalu di muat di dalam kajian ini secara berurutan dan beraturan. Sehingga kajian ini dapat di terima dan dapat menghasilkan kajian yang baik sehingga dapat di manfaatkan untuk banyak kalangan.

\section{Hasil}

Hasil dari metode ini adalah Pelaksanaan Keselamatan dan Kesehatan Kerja (K3) adalah salah satu bentuk upaya untuk menciptakan tempat kerja yang aman, sehat, bebas dari pencemaran lingkungan, sehingga dapat mengurangi dan bebas dari kecelakaan kerja danp enyakit akibat kerja yang pada akhirnya dapat meningkatkan efisiensi dan produktivitas kerja.

Tetapi pada penerapannya Keselamatan dan Kesehatan Kerja (K3) masih sering sekali tidak dengan baik di lakukan terbukti dari banyak tenaga kesehatan yang masih menderita hazard pisikososial di lingkungan kerjanya sehingga 
dapat menghambat tenaga kesehatan dalam melakukan tugas terbauk yang bisa dibertikan tenaga kesehatan kepada pasien.

Oleh karena itu pemahaman tenaga kesehatan dalam pencegahan terjadinya hazard pisikososial ini harus lebih di tingkatkan agar perawat bisa menghindari terjadinta hazard pisiskososial tersebut.

Untuk itu perawat harus tau apa saja faktor-faktor yang dapat menimbulkan hazard pisikososial seperti Penempatan tenaga kerja yang tidak sesuai dengan bakat, minat, kepribadian, motivasi, temperamen atau pendidikannya,sistem seleksi dan klasifikasi tenaga kerja yang tidak sesuai, kurangnya keterampilan tenaga kerja dalam melakukan pekerjaannya sebagai akibat kurangnya latihan kerja yang diperoleh, dan hubungan antara individu yang tidak harmoni dan tidak serasi dalam organisasi kerja. Untuk itu perawat di harapkan dapat menganalisa kesadaran diri agar dapat mengerti dengan perasaan dan masalah diri sendiri di trmpat kerja.

Kecelakaan kerja dapat dicegah bila diketahui penyebabnya. Penyebab kecelakaan kerja dapat dijelaskan melalui beberapa teori. Teori kecelakaan kerja yang pertama adalah Teori Domino yang dikemukakan oleh Heirich, dan kedua adalah modifikasi teori domino yang dikemukakan oleh Frank E Bird dari International Loss Control Institute, yang nantinya akan dikenal sebagai dasar manajemen K3.

\section{Pembahasan}

Hazard merupakan semua sumber, situasi ataupun aktivitas yang berpotensi menimbulkan cedera (kecelakaan kerja) atau penyakit akibat kerja. Risiko dapat didefinisikan sebagai suatu kombinasi dari kemungkinan terjadinya peristiwa yang berhubungan dengan cidera parah atau sakit akibat kerja dan terpaparnya seseorang atau alat pada suatu bahaya. Bahaya psikososial kerja dapat didefinisikan sebagai aspekaspek dari desain kerja, organisasi kerja dan manajemen kerja, serta segala aspek yang berhubungan dengan lingkungan sosial kerja yang berpotensi dapat menyebabkan gangguan pada psikologi dan fisik-fisiologi pekerja ( Cox dan Griffiths,2002) dalam Research on Work-Related Stress 2002.

Masalah psikososial merupakan masalah psikis atau kejiwaan yang timbul sebagai akibat terjadinya perubahan sosial. Oleh karena itu, masalah atau bahaya psikososial dapat terjadi sebagai akibat atau dampak negatif dari adanya proses interaksi sosial seseorang yang buruk. Resiko kerja dan gangguan kesehatan tersebut dapat merugikan para pekerja, yang dapat mengakibatkan pekerja meninggal, keracunan, cacat dan mengidap penyakit kronis sehingga tidak mampu lagi untuk bekerja. Untuk meminimalisasi terjadinya penyakit akibat kerja, maka perlu dilakukan identifikasi bahaya, dimana penyakit akibat kerja bisa disebabkan oleh perilaku pekerja dan kondisi tempat kerja yang kurang baik.

Tekanan fisik/ fisiologi, adalah disebabkan oleh cidera atau sakit, kelelahan karena beban kerja dan durasi kerja panjang, kelelahan karean tidak cukup istirahat, terpajan bahaya terhadap kesehatan, terpajan temperatur ekstrim, kurang oksigen, tekanan 
atmosfer yang bervariasi, gerakan-gerakan yang terpaksa, asupan gula darah kurang, penggunaan obat-obatan. Tekanan psikis, disebabkan oleh beban emosi berat,kelelahan mental, pengambilan keputusan yang ekstrim, rutinitas, monoton, kewaspadaan yang luar biasa, karyawan dengan tuntutan konsentrasi, aktivitas yang tidak berarti, arahan yang membingungkan, memiliki masalah di luar pekerjaan, frustasi.

Faktor ini sebagai akibat organisasi kerja (tipe kepemimpinan, hubungan kerjakomunikasi, keamanan), tipe kerja (monoton, berulang-ulang, kerja berlebihan, kerja kurang, kerja shift, dan terpencil). Manifestasinya berupa stress.Beberapa contoh faktor psikososial yang dapat menyebabkan stress antara lain: 1) Pelayanan kesehatan sering kali bersifat emergency dan menyangkut hidup mati seseorang. Untuk itu pekerja di laboratorium kesehatan di tuntut untuk memberikan pelayanan yang tepat dan cepat disertai dengan kewibawaan dan keramahantamahan 2) Pekerjaan pada unit-unit tertentu yang sangat monoton. 3) Hubungan kerja yang kurang serasi antara pimpinan dan bawahan atau sesama teman kerja.

Bahaya Psiko-sosial, yaitu potensi bahaya yang berasal atau ditimbulkan oleh kondisi aspekaspek psikologis ketenagakerjaan yang kurang baik atau kurang mendapatkan perhatian seperti: 1 . Penempatan tenaga kerja yang tidak sesuai dengan bakat, minat, kepribadian, motivasi, temperamen atau pendidikannya. 2. Sistem seleksi dan klasifikasi tenaga kerja yang tidak sesuai 3. Kurangnya keterampilan tenaga kerja dalam melakukan pekerjaannya sebagai akibat kurangnya latihan kerja yang diperoleh 4. Hubungan antara individu yang tidak harmoni dan tidak serasi dalam organisasi kerja. 5. Pentingnya mempelajari Bahaya Psychosocial dan Stress Kerja adalah agar produktivitas kerja dapat tetap terjaga

Bahaya psikososial ini secara langsung atau tidak akan berpengaruh terhadap konflik fisik dan karyawan seharihari, jika seorang karyawan tidak dapat mengatasi beban bahaya ini dengan baik maka karyawan tersebut akan jatuh dalam kondisi bosan, jenuh, stress dan akan mengalami gangguan serta keluhan penyakit serta menurunkan produktivitas kerja keryawan. Gejala stress : 1. Kepuasan kerja rendah 2. Kinerja yang menurun 3 . Semangat dan energi menjadi hilang 4. Komunikasi tidak lancer 5. Pengambilan keputusan jelek 6. Kreatifitas dan inovasi kurang 7. Bergulat pada tugas-tugas yang tidak produktif. 8. Pengelolaan stress dapat dilakukan melalui 9. pendekatan individu dan organisasi.

Gangguan emosional yang timbul :

\section{Cemas 2. Gelisah 3. Gangguan} kepribadian 4. Penyimpangan seksual 5. Ketagihan alkohol dan psikotropika, Faktor risiko psikologis dalam kecelakaan adalah potensi pikiran, perasaan, dan perilaku yang mungkin terjadi sebagai akibat dari peristiwa

Menurut French dkk. (1974) dalam Cox dkk. (2000), beban kerja dapat dibagi dua, yakni beban kerja secara kualitatif dan beban kerja secara kuantitatif. Beban kerja kuantitatif dilihat berdasarkan 
tingkat kesulitan yang dihadapi pekerja dalam menyelesaikan pekerjaannya, sedangkan beban kerja kualitatif berdasarkan banyaknya tugas yang harus diselesaikan pekerja. Beban kerja cenderung memiliki beban kerja secara kualitatif, hal ini dapat dilihat dari tuntutan waktu pekerjaan untuk melakukan pekerjaan dengan cepat dan tambahan waktu kerja atau lembur kerja yang hampir terjadi setiap hari, serta adanya beban kerja secara kuantitatif juga dirasakan oleh pekerja seperti tingka kesulitan yang dihadapi pekerja dalam menyelesaikan pekerjaannya.

Kondisi faktor hubungan interpersonal dan kepemimpinan yang buruk dapat berdampak pada beberapa masalaah kesehatan. Beberapa hasil penelitian menunjukkan bahwa kondisi dukungan sosial yang rendah dapat berpengaruh terhadap peningkatan risiko masalah kesehatan seperti stres, gangguan kardiovaskuler, penyakit jantung koroner, gangguan mental yang umum, depresi, serta sakit leher. Untuk menjaga kualitas iklim sosial di tempat kerja biasanya didukung oleh adanya dukungan sosial dari rekan kerja melalui beberapa pertemuan dan kebersamaan yang menyenangkan (Eurofound, 2012)

Potensi bahaya psikososial yang teridentifikasi yaitu dinas malam yang melebihi 8 jam, mengani pasien halusinasi, menangani pasien yang defisit perawatan diri, melakukan terapi bermain/TAK. Dapat terjadi resiko stress, rasa takut berlebih, emosi, terpukul, tercakar, panik, mendapat serangan dan perilaku tidak baik dari pasien. Dari Undang-undang No. 1 Tahun 1970 tentang Keselamatan Kerja BAB III syaratsyarat keselamatan kerja pasal 3, dan Kepmenkes RI

Nomor 432/MENKES/SK/IV/2007 tentang pedoman manajemen kesehatan dan keselamatan kerja (K3) di Rumah Sakit bahwa dalam kegiatan rumah sakit berpotensi menimbulkan bahaya fisik, kimia, biologi, ergonomi, dan psikososial, yang dapat membahayakan kesehatan dan keselamatan baik terhadap pekerja, pasien, pengunjung maupun masyarakat di rumah sakit.

\section{Kesimpulan}

Faktor psikososial lingkungan kerja yang ditimbulkan dapat mempengaruhi emosi seseorang antara lain nada suara menjadi tinggi atau keras seperti orang berteriak atau marah-marah saat berbicara dengan orang lain, mudah merasa jengkel atau merasakan perasaan tidak senang dan sulit tidur lelap atau gangguan tidur hal ini disebabkan karena kondisi lingkungan kerja yang bising. Sedangkan suhu panas dan debu dapat menimbulkan efek cepat merasa lelah atau letih.

Kecelakaan kerja dapat dicegah bila diketahui penyebabnya. Penyebab kecelakaan kerja dapat dijelaskan melalui beberapa teori. Teori kecelakaan kerja yang pertama adalah Teori Domino yang dikemukakan oleh Heirich, dan kedua adalah modifikasi teori domino yang dikemukakan oleh Frank E Bird dari International Loss Control Institute, yang 
nantinya akan dikenal sebagai dasar manajemen $\mathrm{K} 3$.

\section{Daftar Pustaka}

Andarini,Desheila.dkk. (2019). Identifikasi

Bahaya Psikososial Pada Buruh

Wanita Di Pabrik Karet. Jurnal

Kesehatan, 1. 61-67

Daniah. Rizki Zulfikri Fauz. (2016). Hubungan Gejala Stres Kerja Dengan Bahaya Pisikososial Pada Pekerja PengumpulTol Cabang Jagorawi Di PT. JASA MARGA (PERSERO) TBK Tahun 2016. Jurnal Ilmu Kesehatan, 8(2). 25-29.

Eurofound. (2012). Health and Well-being at Work: A Report Based on the Fifth European Working Conditions Survey. Dublin.

Fathi, A., \& Simamora, R. H. (2019, March). Investigating nurses' coping strategies in their workplace as an indicator of quality of nurses' life in Indonesia: a preliminary study. In IOP conference series: Earth and Environmental science (Vol. 248, No. 1, p. 012031). IOP Publishing.

Harrianto, R. (2012). Buku Ajar Kesehatan Kerja. Jakarta: Buku Kedokteran EGC.

Indragiri, S., \& Yuttya, T. (2018). Manajemen Resiko K3 Menggunakan Hazard Identification Risk Assessment and Risk Control (HIRARC). Jurnal Kesehatan, 9(1). 39-52.

Kemala. Aliva. (2018). Faktor Pisikososial Lingkungan Kerja (Studi Kasus)
Pada Karyawan Pabrik SSP PT.X.

Jurnal PsikologI, 11(1). 95-106.

Keselamatan Dan Kesehatan Kerja. (2014). Yogyakarta: TIM K3 FT UNY

Myers, S.A. (2012). Patient safety and hospital accreditation : a model for ensuring success. New York : Springer Publishing Company

Simamora, R. H. (2020). Learning of Patient Identification in Patient Safety Programs Through Clinical Preceptor Models. Medico Legal Update, 20(3), 553-556.

Sriningsih, N. \& Marlina, E. (2020). Pengetahuan Penerapan Keselamatan Pasien (Patient Safety) Pada Petugas Kesehatan. Jurnal Kesehatan, 9(1).

Sujoso, Anita Dewi Prahastuti. (2012). Dasar-dasar Keselamatan dan Kesehatan Kerja. Jember: Jember University Press 